\title{
Modelling Curriculum Choice at A-level: Why is Business Studies More Popular than Economics?
}

Ray Bachan

Brighton Business School, University of Brighton

Michael Barrow

Department of Economics, University of Sussex

\section{Abstract}

This paper uses A-level Information System (ALIS) data to quantify the determinants of the choice between Economics and Business Studies at A-level. These subjects are often perceived as close curriculum options and possible substitutes in the UK. Subject choice is modelled using an underlying latent variable approach. On the basis of a series of counterfactual exercises an overall average grade differential, a measure of their comparative difficulty, is estimated to be 1.3 (old) UCAS points, equivalent to approximately two-thirds of a letter grade, in favour of Business Studies. The estimating equation suggests that a unit increase in the grade differential increases the probability of selecting Business Studies over Economics by approximately 12 percentage points. There is evidence that females are less likely to choose Economics over Business Studies and the more able students, in terms of their average GCSE score and mathematical ability, are more likely to select Economics. There is also some evidence of parental background characteristics and ethnicity exerting significant effects on the choice between these two subjects.

\section{Introduction}

Concern regarding falling enrolments on certain A-level courses has been part of the educational landscape in the UK since the introduction of the National Curriculum in 1989. These trends have persisted even though there was a rise in participation rates in post-compulsory education during the 1990s. In particular, 
declining enrolments in the 'hard' mathematics/science-orientated A-level subjects and languages have been highlighted as particular areas for concern (Dearing,1996; Fitz-Gibbon, 1999). The introduction of the Advanced Subsidiary (AS) and the Advanced (AS+A2) qualifications in England and Wales in September 2000 was anticipated to help reverse these unfavourable patterns of enrolments, particularly in the area of mathematics/science and languages. The new examination offers students greater choice and flexibility regarding A-level options particularly in their first year of study. ${ }^{1}$ Indeed, the Royal Society (2005) has recently reported that there have been some modest improvements in A-level enrolments in Chemistry and Mathematics but stress that enrolments in mathematics/sciencerelated A-level options are still relatively low compared to their levels in the early 1990s. However, the new examination has not helped some A-level options, such as modern languages, to recover from the fall in enrolments witnessed in the 1990s.

Despite this concern, there has been relatively little systematic examination of the cause of these observed trends, particularly for A-level subjects outside curriculum areas such as languages and mathematics/science.

A primary motivation for this research is to address this gap in the literature by focusing on two A-level subjects that have witnessed opposite fortunes in enrolment patterns in recent times: Economics and Business Studies. These subjects are often cited as closely related A-level options, and provide examples of a 'difficult' and a 'less challenging' course of study. We analyse factors that can potentially influence the choice between Economics and Business Studies in one particular year using a large dataset, and in so doing develop an econometric methodology that can be employed to address concerns regarding the choice between any two curriculum options. The quantification of the determinants of such choices should enhance understanding of the trends in A-level enrolment noted above.

Research into A-level subject choice has identified several factors that influence the choice of subject. These include: the previous study of the subject; the student's perception of the subject's challenging nature; the likelihood of passing or failing; the interest/enjoyment value of the subject (particularly evident amongst female students); the type of school (i.e. single sex or mixed); the complementarity between A-level subjects (particularly in the sciences); the career aspirations of the student; parental socio-economic characteristics; and the guidance a student receives at school or from parents. Ryrie (1981), Garratt (1985, 1986), McEwan, Curry and Watson (1986), Stables and Stables (1995), Gallagher, McEwan and Knipe (1997), Stables and Wikeley (1997) and Werfhorst, Sullivan and Cheung (2002) provide evidence on these issues. 


\section{The case of Economics and Business Studies}

Between 1992 and 2004, the number of students entered for the full two-year Alevel examinations in Economics in England witnessed a 62\% decline, whereas the numbers entered for A-level examinations in Business Studies increased by $70 \%$ over the period (see Figure A1 in the appendix). It should be noted that by 1995 , the number of students sitting examinations in Business Studies rose above that of Economics for the first time. The pattern described by the data may suggest that, to some extent, students may be substituting A-level Business Studies for A-level Economics. It should also be noted that over the whole period the total number of students taking either subject fell by $18 \%$. This may reflect a strong growth in interest in 'new' subjects offered by the wider post- 16 advanced curriculum offered in the 1990s. ${ }^{2}$ Whether some of these students would have selected Economics over Business Studies if these subjects were not available is difficult to discern, but it is a possibility. Moreover, the figure also reveals that the introduction of AS and the full two-year qualifications in 2000 has had little effect on reversing declining enrolments on the full two-year Economics option.

It is against this background that concern over the declining student numbers on A-level Economics courses has been expressed by economics educators. It is argued that the perceived difficulty between these two subjects is an important factor in explaining Economic's declining enrolments and Business Studies' relative rise in popularity over the past decade. The observed trends are often taken as a reflection of a rational reaction by students to move towards the 'easier' Business Studies and away from the 'harder' Economics (Ashworth and Evans, 2000, 2001; Bachan and Reilly, 2003; Reilly and Bachan, 2005).

Few studies have attempted to explicitly model the choice of Economics over other curriculum options at A-level. The econometric work by Ashworth and Evans (2001) is a notable exception. They find evidence that mathematical ability, prior study of Economics, under achievement in Economics and certain features of the classroom environment are important factors influencing the decision to select Economics at A-level.

The econometric methodology adopted in this paper allows for the control of a variety of individual, family and school characteristics that are assumed, a priori, to influence a student's choice between A-level Business Studies and Economics, in one particular year. A measure that standardises comparative subject 'difficulty' between the comparator subjects is constructed and enters the analysis as an additional regressor in the choice equation. The inclusion of this variable allows for the possible impact that comparative 'difficulty' has on the probability of choosing one subject over another.This measure of difficulty varies by student, so may be better thought 
of as the student's 'aptitude' for the subject. The average of this measure then gives an estimate of the greater difficulty of one subject over the other.

The structure of this paper is as follows. The next section describes the dataset used in the analysis then the following section contains a description of the econometric methodology employed. The penultimate section reports the empirical results and a final section provides a summary of the conclusions.

\section{Data used in the analysis}

The data used are obtained from the ALIS Project administered at the Curriculum, Evaluation and Management Centre (CEM Centre) at Durham University. The specific data employed in this study are based on performance in the 1998 examinations by a sample of Economics and Business Studies candidates and the information they provided on their personal and family characteristics during their first term of a two-year course of study. The sample consists of students aged 16-19 years who completed two or more A-levels (excluding General Studies). Once allowance is made for missing values, 2,052 and 3,453 usable observations are available for Economics and Business Studies respectively.

The set of independent variables used and summary statistics are reported in Table A1 of the appendix. They include a measure of A-level performance, prior attainment (average GCSE score ${ }^{3}$ ), gender, ethnicity, school-type, parental characteristics, examination board, other A-levels studied, the student's desired occupation and attitudes to the subject. It is important to note that for reasons of confidentiality, the data are limited in a number of important respects. It is not possible to identify either schools or colleges by their names or postcodes and therefore not possible to assign certain factors (e.g. location, funding, staff/pupil ratios, numbers on roll, teacher or class characteristics) to the individual level data used here. In addition, it did not prove possible to identify prior attainment in either GCSE Economics or Business Studies (if taken) for the sample of students. The data set employed in this study has been fully described elsewhere (Reilly and Bachan, 2005). For convenience it may be instructive to briefly examine some of the key characteristics of the data set that relate to its current use.

The sample of Economics candidates appear better qualified than their Business Studies counterparts using average GCSE performance measures. A significantly higher proportion of Economics candidates achieved $A / A^{*}$ grades in Mathematics GCSE relative to Business Studies ( $40 \%$ v. $16 \%$ ), with smaller proportions obtaining a grade $\mathrm{C}$ or below ( $20 \%$ v. $45 \%$ ). In terms of A-level performance, almost twice the proportion of Economics candidates secure an A-grade in comparison to their 
Business Studies counterparts but a higher proportion also fail. Economics thus presents a greater spread of grades than does Business Studies.

The gender balance for Business Studies is relatively even. The Economics sample has a slight male dominance, but the proportion of female candidates studying Economics in this sample appears on the high side compared to national estimates for this particular year (DfEE, 1999).

The parents of students studying A-level Economics are more highly represented in the professional job classifications than the parents of those studying Business Studies, whilst the parents of Business Studies students are more represented in the skilled and unskilled classification (see notes to Table A1 in the appendix for the definition of each job category). In terms of parental educational background those students studying Economics have parents educated to a higher level. However, there appear to be few significant differences in terms of parental employment status.

A greater proportion of Economics students tend to find it 'more difficult to get down to work' than those studying Business Studies, perhaps reflecting the more practical nature of the latter subject. But they do appear to think about the subject more than their Business Studies counterparts, perhaps suggesting greater interest in the subject content. It is also interesting to note the higher aspirations of Economics students, with a higher proportion wanting to be employed in the highest professional category, and a greater proportion of Business Studies students wanting to be employed in the lower professional and skilled job categories.

The ethnic mix of those studying A-level Economics is slightly more varied than for the sample of Business Studies candidates. It is worth noting that a high proportion of Economics candidates complement their study of Economics with the study of Mathematics and/or Physics at A-level.

\section{Methodology}

The sample of students in this study have either taken a course in A-level Economics or Business Studies but not both. Subject choice is then modelled in two stages. First, a performance equation is estimated which provides predictions of how each student would perform in each subject. The difference between a student's predicted performance in the two subjects gives an estimate of the student's aptitude for the subjects and hence of their relative difficulty. In the second stage, this predicted difference is used as an explanatory variable in a subject choice equation, with the prior hypothesis that a student's greater aptitude for a subject will make them more likely to choose to study that subject. The first stage of the analysis borrows the methodology employed by Reilly and Bachan 
(2005) to model student performance in Economics and Business Studies and the estimated equation is virtually identical to theirs. The real focus of this paper is the second stage - the subject choice equation.

Given the ordinal nature of the final grade classifications at A-level the first stage of the analysis employs an ordered probit equation (one for each subject) where the observable ordinal variable, $y$, is coded $0,1,2,3,4,5$ on the basis of A-level performance (i.e. $0=\mathrm{N} / \mathrm{U}$ grade, $1=\mathrm{E}, 2=\mathrm{D}, \ldots$, and $5=\mathrm{A}$ ). A full list of the explanatory variables in this model is shown in Table A2 in the appendix. Full details of the methodology utilised to estimate this equation are given in Reilly and Bachan (2005).

We then simulate how the full sample of students would have performed if they had all chosen to study Economics, using the estimated coefficients and threshold parameters $\theta$ from the Economics performance equation. This counterfactual can be expressed as:

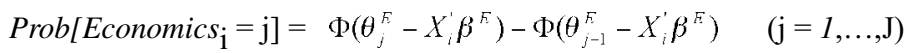

where $\mathrm{j}$ indexes the grade categories and $\mathrm{i}$ indexes students). A further simulation is performed to estimate the performance of all students were they to take the Business Studies course. This uses the coefficients and thresholds from the Business Studies performance equation and can be expressed as:

$\operatorname{Prob}\left[\right.$ Economics $\left._{\mathrm{i}}=\mathrm{j}\right]=\Phi\left(\theta_{j}^{R}-X_{i}^{\prime} \beta^{R}\right)-\Phi\left(\theta_{j-1}^{R}-X_{i}^{\prime} \beta^{B}\right) \quad(\mathrm{j}=1, \ldots \ldots \mathrm{J})$

On the basis of the predicted grade probabilities resulting from expressions [1] and [2], an expected UCAS point score is computed for both Economics and Business Studies for each individual in the sample. This weighted average is constructed using the old UCAS points tariff as weights. ${ }^{4}$ The differential in performance, on the counterfactual assumption that each individual in the sample took both Business Studies and Economics, can be constructed using the results from the simulations. The differential $\left(\mathrm{D}_{\mathrm{i}}\right)$ can be expressed as:

$$
\mathrm{D}_{\mathrm{i}}=S_{i}^{B}-S_{i}^{F}
$$

where $\mathrm{S}_{\mathrm{i}}^{\mathrm{B}}$ and $\mathrm{S}_{i}^{\mathrm{E}}$ are the predicted UCAS point scores in Business Studies and Economics respectively, and $D_{i}$ can be interpreted as a measure of comparative aptitude the student has for the two subjects. A positive differential implies that a student would have performed better, in terms of the predicted UCAS points, if Business Studies were selected. Similarly, a negative grade differential implies that a student would have performed better if Economics were chosen. This differential is employed as an additional regressor in the second stage of our analysis. 
As stated earlier, the primary focus of this paper is on examining the determinants of choosing between Business Studies and Economics. Of particular interest is the impact that comparative subject difficulty has on this decision. In order to explore this issue a standard probit is employed which includes the estimated grade differential as an additional explanatory variable in estimating the structural equation. This model (under standard assumptions) can be expressed as:

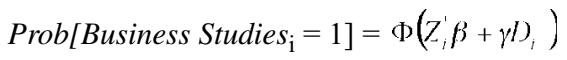

where $Z_{i}$ is a vector of individual characteristics influencing subject choice and $D_{i}$ is the predicted grade differential. The dependent variable is a binary variable which takes on the value of 1 if Business Studies is selected and 0 if Economics is selected. The elements of $Z$ overlap with $X$ but are not identical since we need variable exclusions in order to identify the two equations. The variables common to the two vectors are gender, ethnic background and GCSE background. The performance equation also contains school type, examination board, other A-levels taken and student attitudinal variables (e.g.'I like tests'), which are all excluded from the subject choice equation. The latter also contains parental characteristic variables, the student's desired job characteristics and, of course, the grade differential.

The variance-covariance matrix of the choice model is corrected for heteroscedasticity of an unknown form, although it is not corrected for clustering by institution unlike the performance equation.

\section{Results}

As A-level performance in Economics and Business Studies is not the primary focus of this paper, the performance equations are not the subject of detailed discussion here. The estimated equations are shown in Table A2 in the appendix. These are very similar to the results in Reilly and Bachan (2005) and confirm some established findings of the importance of prior attainment, gender, examination board and school type on A-level performance. The principal difference from the result in Reilly and Bachan (2005) is the inclusion of the variables relating to the students' attitudes towards their studies. Not surprisingly, these variables do have an influence upon performance, more so in the case of Economics than Business Studies. It is interesting to note that liking lessons does not appear to influence the final grade achieved in either subject, though a positive attitude to tests and to work does help. The inclusion of these new variables makes little difference in terms of the grade predictions and the subsequent subject choice equation. We achieve very similar results if we use the same original specification of the performance equation from Reilly and Bachan (2005). 
The modelling technique adopted then simulates how, on average, each individual in the sample of students would have performed if they had all selected one subject over the other. The results from this counterfactual are reported in Table 1. Columns two and three of Table 1 report the actual distribution of candidates across the six grade categories and the last two columns report the results from the simulation. The actual proportion of Economics students achieving a grade $\mathrm{A}-\mathrm{C}$ is about $59 \%$ and the proportion failing is $13 \%$. The comparable figures for the Business Studies cohort are $57 \%$ and $11 \%$ respectively. The counterfactual suggests that if the Business Studies students in the sample had selected Economics the proportion gaining a grade $\mathrm{C}$ or better would be about $36 \%$, substantially less than the real Economics students. Specifically, only $8 \%$ of students would have been allocated a grade A compared to $23 \%$ of Economics students who were actually allocated this grade. Moreover, on the basis of this simulation the proportion of students failing would rise from $13 \%$ to about $28 \%$ - two and a half times the

Table 1 Predicted A-level outcomes for Business Studies and Economics samples

\begin{tabular}{lcccc}
\hline A-level grade & $\begin{array}{c}\text { Actual } \\
\text { Economics } \\
\text { outcome }\end{array}$ & $\begin{array}{c}\text { Actual Business } \\
\text { Studies } \\
\text { outcome }\end{array}$ & $\begin{array}{c}\text { Predicted } \\
\text { Economics } \\
\text { outcome for } \\
\text { Business Studies } \\
\text { students }\end{array}$ & $\begin{array}{c}\text { Predicted } \\
\text { Business Studies } \\
\text { outcome for } \\
\text { Economics } \\
\text { students }\end{array}$ \\
\hline A & 0.227 & 0.122 & 0.080 & 0.231 \\
B & 0.175 & 0.218 & 0.112 & 0.269 \\
C & 0.192 & 0.229 & 0.170 & 0.213 \\
D & 0.166 & 0.187 & 0.198 & 0.142 \\
E & 0.110 & 0.133 & 0.163 & 0.084 \\
N/U & 0.130 & 0.111 & 0.277 & 0.062 \\
Average points & 5.7 & 5.4 & 3.8 & 6.5 \\
Average predicted & & & & \\
points differential & & & & \\
\hline
\end{tabular}

Notes to table:

a Predicted Economics outcomes for all students based on using estimated coefficients from the ordered probit model for Economics performance. See equation [1] in the text.

b Predicted Business Studies outcomes for all students based on using estimated coefficients from the ordered probit model. See equation [2] in the text.

c The average point scores are based on weighted averages computed using the UCAS points tariff: $A=10, B=8, C=6, D=4, E=2, N / U=0$.

d The average predicted points differential is computed as the average predicted Business Studies points minus the average predicted Economics points for all students in the sample. 
proportion that actually failed Business Studies. Similarly, it should be noted that the average Economics score falls from 5.7 to 3.8 , a drop of a full letter grade.

The opposite simulation is now performed using the estimated Business Studies coefficients and threshold parameters. The results from this exercise are reported in the last column in Table 1. If the Economics students chose Business Studies, the proportion allocated an A-level grade C or better would be about $71 \%$, greater than the proportion of Business Studies student who actually achieved these grades $(57 \%)$. The failure rate is also lower than the actual proportion that failed Business Studies. In this case the average GCSE score for the Economics students is higher than the Business Studies average by about half a grade. These results reflect this higher ability of the Economics students (as evidenced by GCSE scores noted earlier) and the greater degree of difficulty of Economics as a subject.

These results may be re-interpreted in terms of the old A-level point scores for the average student (see the notes to Table 1). This information is provided in the bottom two rows of Table 1. Economics students achieved an average score of 5.7 UCAS points per entry, while the average Business Studies student secured a score of 5.4. However, if Business Studies students had taken Economics A-level, their predicted average grade is just 3.8. Similarly, if the Economics students had taken Business Studies, the predicted average score is 6.5 (better than the average Economics grade for these students).

If all students were to take Economics then the average UCAS point score is 4.5 (it makes no difference if we use the actual or predicted score for Economics students). However, if the sample of students all took Business Studies then the average score turns out to be 5.8. The overall average grade differential is thus computed as 1.3 UCAS points (approximately two-thirds of a letter grade). This particular result could be interpreted as a measure of the average level of 'difficulty' between the two subjects suggesting that Economics is 'harder' or more challenging than Business Studies. (An alternative explanation is that students, on average, have a greater aptitude for Business Studies than Economics. It is impossible with the data we have to discriminate between these alternatives.) A 'grade maximising' student would choose Business Studies rather than Economics.

The estimated coefficients for the choice equation are reported in Table 2, reporting the marginal effects. The estimated gender effect suggests that, on average and ceteris paribus, males are five percentage points less likely to choose Business Studies over Economics, compared to females, 5 this being significant at the $1 \%$ level. There are well-defined effects associated with the Asian and Chinese ethnic control variables. For instance, Asian students, on average and ceteris paribus, are about 16 percentage points less likely to choose Business Studies over Economics, 
compared to their white counterparts. The average GCSE score also exerts a significant effect on the decision to study either Economics or Business Studies. The point estimate implies that a unit increase in the average GCSE score reduces the probability of selecting Business Studies over Economics by nearly eight percentage points. This could be interpreted as indicating that the more able, in terms of their average GCSE scores, are more likely to select Economics given the

Table 2 Maximum likelihood structural probit estimates for student choice of Business Studies over Economics A-level

\begin{tabular}{|c|c|c|}
\hline \multicolumn{2}{|l|}{ Variable } & Marginal effects \\
\hline \multicolumn{2}{|l|}{ Constant } & $1.264(0.255)^{* * *}$ \\
\hline \multicolumn{2}{|l|}{ Male } & $-0.051(0.015)^{* * *}$ \\
\hline \multirow[t]{6}{*}{ Ethnic background: } & White & $f$ \\
\hline & Black & $-0.059(0.047)$ \\
\hline & Asian & $-0.159(0.034)^{* * *}$ \\
\hline & Chinese & $-0.228(0.069)^{* * *}$ \\
\hline & Other & $0.039(0.051)$ \\
\hline & Mother tongue - English & $0.028(0.036)$ \\
\hline \multirow[t]{5}{*}{ GCSE background: } & Average GCSE score & $-0.076(0.014)^{* * *}$ \\
\hline & GCSE Maths - A/A* & $-0.127(0.026)^{* * *}$ \\
\hline & GCSE Maths - B & $-0.105(0.019)^{* * *}$ \\
\hline & GCSE Maths - C & $f$ \\
\hline & GCSE Maths - D & $0.078(0.039)^{*}$ \\
\hline \multicolumn{3}{|l|}{ Parental characteristics: } \\
\hline \multirow[t]{5}{*}{ Mother's job characteristics } & Professional I & $0.008(0.028)$ \\
\hline & Professional II & $f$ \\
\hline & Skilled (manual/non-manual) & $0.036(0.019)^{*}$ \\
\hline & Unskilled (manual/non-manual) & I) $0.047(0.028)^{*}$ \\
\hline & Category missing & $0.049(0.034)$ \\
\hline \multirow[t]{5}{*}{ Mother's employment status } & Unemployed & $0.006(0.051)$ \\
\hline & Full-time employment & $f$ \\
\hline & Part-time employment & $-0.024(0.017)$ \\
\hline & Self-employed & $0.025(0.030)$ \\
\hline & Other & $-0.030(0.021)$ \\
\hline \multirow[t]{3}{*}{ Mother's education } & Secondary education & $f$ \\
\hline & Further education & $-0.026(0.017)$ \\
\hline & Higher education & $-0.067(0.023)^{* * *}$ \\
\hline
\end{tabular}


Table 2 (continued) Maximum likelihood structural probit estimates for student choice of Business Studies over Economics A-level

\begin{tabular}{|c|c|c|}
\hline Variable & & Marginal effects \\
\hline \multirow[t]{5}{*}{ Father's job characteristics } & Professional I & $-0.038(0.017)^{* *}$ \\
\hline & Professional II & $f$ \\
\hline & Skilled (manual/non-manual) & $0.042(0.020)^{* * *}$ \\
\hline & Unskilled (manual/non-manual) & l) $0.051(0.032)$ \\
\hline & Category missing & $0.018(0.045)$ \\
\hline \multirow[t]{5}{*}{ Father's employment status } & Unemployed & $-0.014(0.044)$ \\
\hline & Full -time employment & $f$ \\
\hline & Part-time employment & $-0.038(0.045)$ \\
\hline & Self-employed & $-0.027(0.020)$ \\
\hline & Other & $-0.022(0.030)$ \\
\hline \multirow[t]{3}{*}{ Father's education } & Secondary education & $f$ \\
\hline & Further education & $-0.017(0.019)$ \\
\hline & Higher education & $-0.010(0.018)$ \\
\hline \multicolumn{3}{|c|}{ Student's (desired) job characteristics } \\
\hline & Professional I & $-0.090(0.016)^{* * *}$ \\
\hline & Professional II & $f$ \\
\hline & Skilled (manual/non-manual) & $0.070(0.033)^{* *}$ \\
\hline & Unskilled (manual/non-manual)- & I) $-0.304(0.080)^{* * *}$ \\
\hline & Category missing & $-0.129(0.033)^{* * *}$ \\
\hline \multicolumn{2}{|l|}{ Predicted grade differential } & $0.123(0.009)^{* * *}$ \\
\hline \multicolumn{2}{|l|}{ Log-likelihood value } & -3040.365 \\
\hline \multicolumn{2}{|l|}{ Pseudo-R2 } & 0.164 \\
\hline \multicolumn{2}{|l|}{ Number of observations } & 5505 \\
\hline
\end{tabular}

Notes to table:
a ${ }^{*}$ significant at $10 \%,{ }^{* *}$ significant at $5 \%,{ }^{* * *}$ significant at $1 \%$.
b $f$ denotes category omitted in estimation.
c Robust standard errors corrected for heteroscedasticity.
d Pseudo- $R^{2}$ based on the McFadden measure. 
alternative of Business Studies, and this reflects the greater apparent difficulty of Economics as a subject.

It is widely accepted that competence in basic mathematics enhances the study of Economics (and, implicitly, to a greater extent than for Business Studies). If the choice of subject is exclusively between Economics and Business Studies it may be expected that the more mathematically able would select Economics, given their comparative advantage in this particular skill. Ashworth and Evans (2001) find evidence of this particular effect. The results here suggest that the top GCSE maths grades are highly significant and so provide further evidence in support of this assertion. For instance, students who attain a grade A or A* in GCSE maths are about 13 percentage points, on average and ceteris paribus, less likely to choose Business Studies over Economics than students who only achieved a grade C. A similar finding is also noted for students with a grade $B$ in GCSE maths and a D grade increases the probability of opting for Business Studies.

There are some interesting findings associated with the parental socio-economic background controls. In broad outline, the father's job characteristics and mother's educational qualifications seem to matter most. Having a father in the professional job category reduces the chances of choosing Business Studies by four percentage points, relative to the baseline 'professional II' category, and by eight percentage points relative to the skilled worker category.

Having an educated mother increases the chances of studying Economics. Compared to secondary education only, further education increases the probability of studying Economics by nearly three percentage points, higher education by nearly seven. The latter effect is significant at the $1 \%$ level; the former is not significant. The effects of father's education are both smaller and less well determined. This result may in part be caused by the relatively rarity of higher education amongst mothers: only $19 \%$ of the sample has higher education compared to $31 \%$ of fathers and hence it is a better discriminator.

The student's aspirations regarding occupational type exert significant effects on the probability of choosing between these two subjects. In particular, students who prefer to work in professional I occupations are, on average and ceteris paribus, about nine percentage points less likely to choose Business Studies over Economics, compared to students who prefer to work in professional II occupations. Students who would like to work in skilled occupations are, on average and ceteris paribus, about seven percentage points more likely to choose Business Studies over Economics. Both these effects are significant: at the $1 \%$ and $5 \%$ levels respectively. The large (30 percentage points) and significant effect associated with a desired unskilled occupation is probably spurious, despite the low significance level. The result is 
derived from just 38 sample observations expressing this preference, with slightly more (proportionately) choosing Economics over Business Studies as a subject.

Finally, the coefficient on the estimated average grade differential (the measure of student aptitude for the subject) exerts a large and significant effect on student choice. A unit increase in the differential (equivalent to half a letter grade) raises the probability of choosing Business Studies over Economics, on average and ceteris paribus, by 12 percentage points. This is clearly a substantial effect and suggests that, even if students have some difficulty in assessing their own aptitude for the subjects, they are likely to favour the subject in which they have a relative advantage. Their choice might reflect a greater enjoyment of the subject, based on aptitude, or be the result of grade maximising behaviour. We noted earlier that the average predicted grade difference between the two subjects was 1.3 letter grades and this would suggest an increase of about $16 \%$ points in the probability of choosing Business Studies over Economics. For example, this would turn indifference between the two subjects into at 58:42 ratio in favour of Business Studies, resulting in $38 \%$ more students opting for that subject. That fact, however, only accounts for a small proportion of the approximate $2.5: 1$ ratio between the subjects revealed in Figure A1.

Alternatively, one can measure the grade differential elasticity, at 0.25 , by multiplying the marginal effect $(0.12)$ by the ratio of means $(1.3 / 0.63)$. Hence, for example, a $10 \%$ increase in the grade differential results in a $2.5 \%$ increase in the probability of choosing Business Studies over Economics.

\section{Conclusions}

The core theme of this paper was to systematically examine the factors that are likely to influence a student's choice of subject at A-level. The econometric analysis presented provides evidence of the factors that influence the choice between Economics and Business Studies. ${ }^{6}$

The findings highlight the important role that comparative subject difficulty or student aptitude plays in influencing the choice between Economics and Business Studies at A-level, and provides further support for Ashworth and Evans (2000) who conclude that 'economists are grading students away from the subject'. If grademaximisation is considered to be an important determinant of subject choice, a significant portion of the more poorly qualified Economics candidates would be better off doing Business Studies and this could be a major contributory factor to the former's declining enrolments. Moreover, the signals sent by the examination boards on the challenging nature of the two subjects under examination may in part be a reflection of the marking criteria and grade allocation policies. Given the 
pattern of examination entries shown in Figure A1 Economics still proves vulnerable to attrition even after the reforms to the A-level examination in 2000 . If relatively low A-level achievement in Economics is indeed a consequence of the marking criteria adopted by the examination boards, then a review of syllabus content and the marking and grading criteria set by the examination boards may be warranted.

The econometric analysis also provides further evidence on a variety of other factors that influence the choice between these two subjects at A-level. The issue of female under-representation on Economics courses has been internationally recognised (Hovarth, Beaudin and Wright, 1992; Dyan and Rouse, 1997; Ferber, 1995; Greene, 1997; Burnett, 1997; Ashworth and Evans, 1999; Jensen and Owen, 2000). The evidence suggests that females are less likely than males to choose Economics over Business Studies at A-level, and also confirms the empirical findings of Ashworth and Evans (2001) who detect a significant positive effect for women choosing Business Studies over Economics. It should be noted that they also find that females are more likely to choose science and arts subjects rather than Economics at A-level. The potential reasons for the apparent female dislike of Economics relative to males are likely to be varied and complex. These range from a lack of female skills in spatial relationships (Williams, Waldauer and Duggal, 1992) to the lack of female role models and a critical mass of women studying the discipline (Ashworth and Evans, 1999, 2001). It is conceded that no useful insights can be offered to explain the mechanisms at play, but after controlling for a variety of factors the effect still remains. Ashworth and Evans (1999) suggest that more effective marketing of Economics to potential female students would in part help to reverse this apparent lack of female interest in Economics.

The results provide further supportive evidence on the important role played by prior attainment at GCSE and mathematical ability in selecting Economics over Business Studies at A-level (Ashworth and Evans, 2001). Ashworth and Evans (2001) also find evidence that the more able students, in terms of their GCSE score and mathematical ability, are more likely to choose science subjects over Economics. They point out that this poses certain dilemmas for economics educators who want to attract otherwise bright students to the subject. Raising the mathematical requirement of the subject may prove to be counter-productive in that the more able, mathematically, may opt for other equally challenging subjects. Economics educators need to be aware of this in regard to curriculum development and carefully review the mathematical requirement of the syllabus offered to prospective students.

It is argued that parents' interests are channelled to their children who are likely to choose subjects close to such interests (Dryler, 1998; Davies and Guppy, 1997; 
Jonsson, 1999; Hansen, 1997; Werfhorst, Sullivan and Cheung, 2002). Moreover, this literature also suggests that children choose subjects that correspond closely to their parents' position in the economic and cultural hierarchy. There is some support for the notion that parental characteristics influence the choice of A-level in the present study. The influence of parental background characteristics was found to be mediated through both fathers' and mothers' characteristics. In particular, there is evidence that maternal education level has some impact on the choice of subject.

The specific focus of this paper was to examine the factors that influence subject choice at A-level for two subjects that are often perceived as possible substitutes. In particular, we examine the extent to which the perceived difficulty of the subject impacts upon students' choices. The methodology adopted in this paper has broader applications for educationalists engaged in research on A-level subject choice (and comparative subject difficulty), and provides sharp insights into the determinants governing such choices. It may prove fruitful to examine the role these factors play in influencing the choice of continuing with an A-level option beyond the first year of study, where possible substitution exists and students have greater experience of how difficult a subject is. We believe the econometric methodology used in this paper can be easily adapted to explore this issue and provides an avenue for further research. It was not possible to explore the extent to which factors relating to classroom environment and prior study influence the choice between A-level subjects. However, this does represent a further avenue to explore using a richer set of individual level data than that employed in the present study. On a more general level the findings presented in this paper offers potential evidence on the factors that may contribute to the relative decline in student enrolments on the 'hard' mathematics/science-orientated A-levels. This decline can be partly explained by the comparative difficulty of these subjects compared to their'softer' A-level alternatives. This issue is exacerbated by the greater focus on results, both for schools in respect of league tables and for students in terms of later university entrance. It may be the case that 'hard' subjects require a final grade adjustment commensurate with their comparative difficulty to reverse the observed recent enrolment trends in these subjects (Dearing, 1996; Fitz-Gibbon and Vincent, 1994; Fitz-Gibbon, 1999). Where possible substitutability exists between subjects the analysis suggests that the 'harder' of the two will lose in terms of enrolments. Quantifying the impact of factors that influence the selection of subjects at A-level is clearly useful to the policy maker engaged in curriculum design. 


\section{Appendix}

Figure A1. Total number of students taking A-level examinations in Economics and Business Studies: England 1992-2004

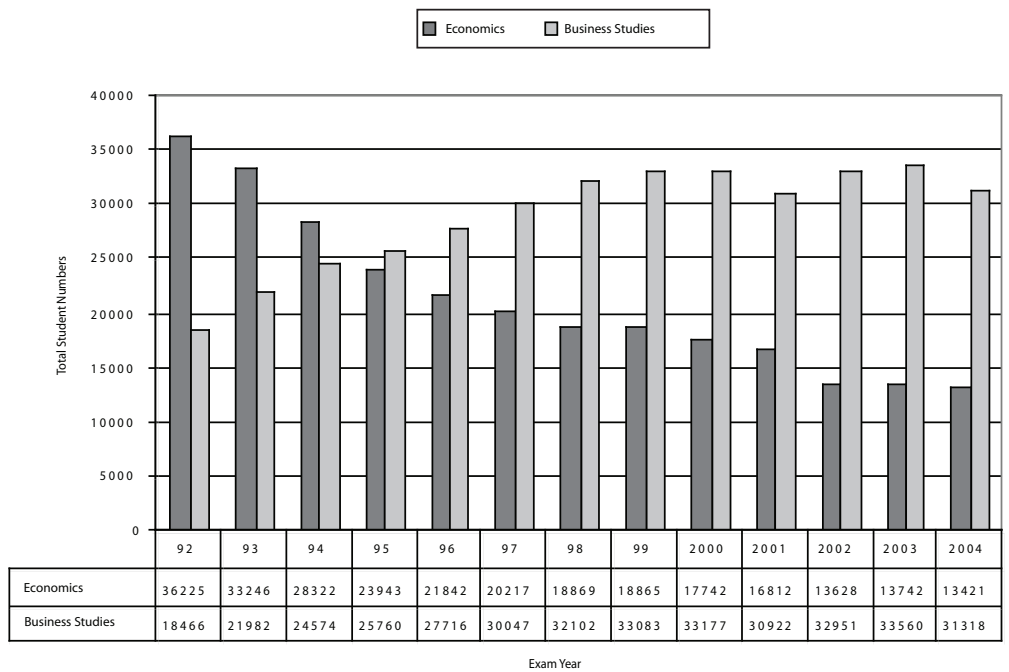

Source: DfEE (various years) Statistics of Education: Public Examinations GCSE and GCE, London: HMSO.

Table A1 Summary statistics for Economics and Business Studies samples

\begin{tabular}{|c|c|c|c|}
\hline Variable & Economics & $\begin{array}{l}\text { Business } \\
\text { Studies }\end{array}$ & $\begin{array}{c}\text { z-score/chi- } \\
\text { squared tests }\end{array}$ \\
\hline
\end{tabular}

\section{A-level grade performance:}

\begin{tabular}{lllr} 
A & 0.227 & 0.122 & 10.20 \\
B & 0.175 & 0.218 & -3.86 \\
C & 0.192 & 0.229 & -3.34 \\
D & 0.166 & 0.187 & -2.07 \\
E & 0.110 & 0.133 & -2.20 \\
N/U & 0.130 & 0.111 & 2.13 \\
$\chi_{5}^{2}$ & & & $120.47(0.00)$ \\
Gender: & & & \\
Male & 0.579 & 0.510 & 4.950 \\
\hline
\end{tabular}


Table A1 (continued) Summary statistics for Economics and Business Studies samples

\begin{tabular}{|c|c|c|c|}
\hline Variable & Economics & $\begin{array}{l}\text { Business } \\
\text { Studies }\end{array}$ & $\begin{array}{l}\text { z-score/chi- } \\
\text { squared tests(a) }\end{array}$ \\
\hline \multicolumn{4}{|l|}{ Ethnic background: } \\
\hline White & 0.827 & 0.888 & -6.368 \\
\hline Black & 0.026 & 0.026 & 0.000 \\
\hline Asian & 0.107 & 0.064 & 5.668 \\
\hline Chinese & 0.014 & 0.007 & 2.510 \\
\hline Other & 0.026 & 0.015 & 2.763 \\
\hline$\chi_{4}^{2}$ & & & $50.13(0.00)$ \\
\hline Mother tongue - English & 0.914 & 0.944 & -4.452 \\
\hline \multicolumn{4}{|l|}{ GCSE background: } \\
\hline GCSE score & 6.167 & 5.666 & 24.530 \\
\hline GCSE Maths - A/A* & 0.402 & 0.162 & 20.609 \\
\hline GCSE Maths - B & 0.398 & 0.385 & 0.897 \\
\hline GCSE Maths - C & 0.185 & 0.393 & -16.428 \\
\hline GCSE Maths - D & 0.015 & 0.060 & -7.886 \\
\hline$\chi_{3}^{2}$ & & & $532.13(0.00)$ \\
\hline \multicolumn{4}{|l|}{ School type: } \\
\hline LEA & 0.299 & 0.222 & 6.389 \\
\hline Grant maintained & 0.206 & 0.116 & 9.118 \\
\hline Private & 0.208 & 0.113 & 9.646 \\
\hline Sixth-form college & 0.170 & 0.294 & -10.414 \\
\hline Further education college & 0.117 & 0.255 & -12.432 \\
\hline$\chi_{4}^{2}$ & & & $378.27(0.00)$ \\
\hline \multicolumn{4}{|l|}{ Student's attitude to subject: } \\
\hline I do not find it hard to get down to work & 0.524 & 0.572 & -3.439 \\
\hline I look forward to lessons & 0.494 & 0.517 & -1.671 \\
\hline I like exams and tests & 0.162 & 0.166 & -0.326 \\
\hline $\begin{array}{l}\text { I think about the subject a lot, even } \\
\text { in my spare time }\end{array}$ & 0.330 & 0.259 & 5.671 \\
\hline \multicolumn{4}{|l|}{ Student's desired occupational category } \\
\hline Professional I & 0.684 & 0.498 & 13.664 \\
\hline Professional II & 0.218 & 0.358 & -11.029 \\
\hline Skilled (manual/non-manual) & 0.027 & 0.075 & -7.372 \\
\hline Unskilled (manual/non-manual) & 0.009 & 0.005 & 1.628 \\
\hline Category missing & 0.062 & 0.064 & -0.269 \\
\hline$\chi_{4}^{2}$ & & & $287.12(0.00)$ \\
\hline
\end{tabular}


Table A1 (continued) Summary statistics for Economics and Business Studies samples

\begin{tabular}{|c|c|c|c|}
\hline Variable & Economics & $\begin{array}{c}\text { Business } \\
\text { Studies }\end{array}$ & $\begin{array}{c}\text { z-score/chi- } \\
\text { squared tests(a) }\end{array}$ \\
\hline
\end{tabular}

\section{Parental characteristics:}

Mother's job characteristics

Professional I(b)

$\begin{array}{llr}0.097 & 0.067 & 4.088 \\ 0.258 & 0.194 & 5.503 \\ 0.498 & 0.563 & -4.717 \\ 0.090 & 0.120 & -3.429 \\ 0.057 & 0.056 & 0.220\end{array}$

Professional II(c)

Skilled (manual/non-manual)(d)

Unskilled (manual/non-manual)(e)

$59.77(0.00)$

$\chi_{4}^{2}$

Mother's employment status

Unemployed

0.018

0.024

$-1.350$

Full-time employment

0.375

0.391

$-1.110$

Part-time employment

0.323

0.330

$-0.598$

0.070

0.069

0.094

Other

0.214

0.186

2.504

$\chi_{4}^{2}$

$8.33(0.08)$

Mother's education

Secondary education

0.393

0.533

$-10.129$

Further education

0.352

0.317

2.629

Higher education

0.255

0.150

9.729

$\chi_{2}^{2}$

Father's job characteristics

Professional I(b)

0.394

0.278

8.980

Professional II(c)

0.373

0.394

$-1.515$

Skilled (manual/non-manual)(d)

0.169

0.240

$-6.210$

Unskilled (manual/non-manual)(e)

0.037

0.059

$-3.730$

Category missing

0.027

0.029

$-0.422$

$\chi_{4}^{2}$

Father's employment status

Unemployed

0.027

0.032

$-1.016$

Full-time employment

0.689

0.705

$-1.274$

Part-time employment

0.029

0.023

1.206

Self-employed

0.194

0.181

1.222

Other

0.061

0.059

0.396

$\chi_{4}^{2}$ 
Table A1 (continued) Summary statistics for Economics and Business Studies samples

\begin{tabular}{|c|c|c|c|}
\hline Variable & Economics & $\begin{array}{l}\text { Business } \\
\text { Studies }\end{array}$ & $\begin{array}{c}\text { z-score/chi- } \\
\text { squared tests(a) }\end{array}$ \\
\hline \multicolumn{4}{|l|}{ Father's education } \\
\hline Secondary education & 0.348 & 0.456 & -7.917 \\
\hline Further education & 0.266 & 0.287 & -1.712 \\
\hline Higher education & 0.386 & 0.257 & 10.188 \\
\hline$\chi_{2}^{2}$ & & & $108.35(0.00)$ \\
\hline \multicolumn{4}{|l|}{ Examination board: } \\
\hline AEB & 0.245 & 0.755 & -42.590 \\
\hline EDEXCEL & 0.475 & 0.098 & 35.046 \\
\hline NEAB & 0.136 & 0.023 & 16.992 \\
\hline OCR & 0.144 & 0.124 & 2.137 \\
\hline$\chi_{3}^{2}$ & & & $1616.9(0.00)$ \\
\hline \multicolumn{4}{|l|}{ Other A-levels taken: } \\
\hline Mathematics & 0.328 & 0.176 & 13.093 \\
\hline Physics & 0.069 & 0.028 & 7.132 \\
\hline English & 0.258 & 0.274 & -1.286 \\
\hline Statistics \& Accounting & 0.013 & 0.018 & -1.289 \\
\hline Science ${ }^{(f)}$ & 0.165 & 0.196 & -2.881 \\
\hline Social Sciences (g) & 0.344 & 0.339 & 0.395 \\
\hline Humanities (h) & 0.219 & 0.161 & 5.424 \\
\hline Modern Languages & 0.147 & 0.104 & 4.692 \\
\hline Arts(i) & 0.096 & 0.194 & -9.711 \\
\hline Number of observations & 2052 & 3453 & \\
\hline
\end{tabular}

Notes to table:

(a) Z-scores are used to test differences in proportions between Economics and Business Studies and $t$-tests are used to test differences in means. The appropriate critical value at the 0.05 level using a two-tailed test is \pm 1.96 .

(b) Professional I include Doctor, Lawyer, Director, Architect, Accountant.

(c) Professional II include Teacher, Aircraft Pilot, Engineer, Manager.

(d) Skilled include Nurse, Supervisor, Carpenter, Cook, Electrician, Plumber.

(e) Unskilled include Kitchen worker, Labourer, Cleaner, Postal delivery worker.

(f) Science subjects include Biology, Chemistry, Electronics and Computing.

(g) Social Sciences include Sociology and Psychology.

(h) Humanities include Classical Civilisation, Environmental Studies, Geography, Politics, History, Home Economics, Latin, Law and Religious Studies.

(i) Arts subjects include Art, Communication Studies, Design and Technology, Graphical Communication, Music, Photography, Theatre Studies and Performing Arts. 
Table A2 Maximum likelihood ordered probit estimates for performance in Economics and Business Studies

\begin{tabular}{|c|c|c|}
\hline Variable & Business Studies & Economics \\
\hline Constant & -5.155 & -6.300 \\
\hline Male & $1.454(0.321)^{* * *}$ & $0.239(0.062)^{* * * *}$ \\
\hline \multicolumn{3}{|l|}{ Ethnic background: } \\
\hline Asian & $-0.140(0.095)$ & $-0.101(0.101)$ \\
\hline Black & $-0.022(0.116)$ & $-0.05(0.154)$ \\
\hline Chinese & $-0.301(0.231)$ & $-0.509(0.211)^{* *}$ \\
\hline Other & $-0.150(0.150)$ & $0.132(0.157)$ \\
\hline Mother tongue - English & $-0.052(0.106)$ & $-0.039(0.112)$ \\
\hline \multicolumn{3}{|l|}{ GCSE background: } \\
\hline GCSE score & $1.109(0.050)^{* * *}$ & $1.192(0.051)^{* * *}$ \\
\hline GCSE score x Male & $-0.234(0.056)^{* * *}$ & $0(0)$ \\
\hline GCSE Maths - A/A* & $0.323(0.078)^{* * *}$ & $0.371(0.099)^{* * *}$ \\
\hline GCSE Maths - B & $0.203(0.046)^{* * *}$ & $0.151(0.074)^{* *}$ \\
\hline GCSE Maths - D & $-0.076(0.082)$ & $-0.189(0.222)$ \\
\hline \multicolumn{3}{|l|}{ School type: } \\
\hline FE college & $-0.222(0.069)^{* * *}$ & $-0.065(0.085)$ \\
\hline Grant maintained & $0.121(0.067)$ & $-0.241(0.1)^{* *}$ \\
\hline Private & $-0.005(0.067)$ & $-0.047(0.074)$ \\
\hline Sixth form college & $0.122(0.052)^{* *}$ & $-0.016(0.075)$ \\
\hline GM x Male & $\mathrm{f}$ & $0.375(0.123)^{* * *}$ \\
\hline FE x Male & $0.202(0.083)^{* *}$ & $\mathrm{f}$ \\
\hline \multicolumn{3}{|l|}{ Examination board: } \\
\hline EDEXEL & $-0.389(0.062)^{* * * *}$ & $0.259(0.061)^{* * *}$ \\
\hline NEAB & $0.427(0.123)^{* * *}$ & $-0.03(0.082)$ \\
\hline OCR & $-0.115(0.058)^{* *}$ & $0.221(0.082)^{* * * *}$ \\
\hline \multicolumn{3}{|l|}{ Other A-levels taken: } \\
\hline Maths & $0.124(0.061)^{* *}$ & $-0.04(0.068)$ \\
\hline English & $0.139(0.047)^{* * *}$ & $-0.119(0.066)$ \\
\hline Physics & $0.018(0.117)$ & $0.03(0.106)$ \\
\hline Statistics \& Accounting & $0.195(0.140)$ & $-0.151(0.223)$ \\
\hline Science & $0.074(0.052)$ & $-0.106(0.074)$ \\
\hline Humanities & $0.276(0.054)^{* * *}$ & $0.273(0.067)^{* * * *}$ \\
\hline Social Science & $0.255(0.044)^{* * *}$ & $0.139(0.061)^{* *}$ \\
\hline Arts & $0.054(0.070)$ & $-0.265(0.124)^{* *}$ \\
\hline Modern Language & $0.009(0.068)$ & $-0.14(0.08)$ \\
\hline Arts $\times$ Male & $-0.279(0.092)^{* * *}$ & $-0.336(0.163)^{* *}$ \\
\hline
\end{tabular}


Table A2 (continued) Maximum likelihood ordered probit estimates for performance in Economics and Business Studies

\begin{tabular}{lcc}
\hline Variable & Business Studies & Economics \\
\hline Attitudinal variables: & & \\
Not hard to work & $0.185(0.039)^{* * *}$ & $0.247(0.072)^{* * *}$ \\
Think about subject & $0.097(0.043)^{* *}$ & $0.179(0.057)^{* * *}$ \\
Log-likelihood value & -5177.3 & -2863.8 \\
Pseudo-R2 & 0.144 & 0.209 \\
\hline Observations & 3453 & 2052 \\
\hline
\end{tabular}

\section{References}

Ashworth, J., and Evans, L. (1999) 'Lack of knowledge Deters Women from Studying Economics', Educational Research, 41, 209-227.

Ashworth, J., and Evans, L. (2000) 'Economists are Grading Students Away from the Subject', Educational Studies, 26, 475-487.

Ashworth, J., and Evans, L. (2001) 'Modelling Student Choice at Secondary and Tertiary Level: A Cross-section Study', Journal of Economic Education, 32 (4), 311-320.

Bachan, R., and Reilly, B. (2003) 'A Comparison of Academic Performance in A-level Economics Between Two Years', International Review of Economics Education, 1, (2) 8-24.

Burnett, N. (1997) 'Gender Economics Courses in Liberal Arts Colleges', Journal of Economic Education, 28 (4) 369-376.

Davies, S., and Guppy, N. (1997) 'Fields of Study, College Selectivity, and Student Inequalities in Higher Education', Social Forces, 75, 1417-1438.

Dearing, R. (1996) Review of Qualifications for 16-19 Year Olds, London: National Curriculum Council and School Assessment Council.

DfEE (1999 and various issues), Statistics of Education: Public Examinations GCE and GCSE, London: HMSO.

Dryler, H. (1998) ‘Parental Role Models, Gender and Educational Choice', British Journal of Sociology, 49, 375-398.

Dynan K.E., and Rouse, C.E. (1997) 'The Under-representation of Women in Economics: A Study of Undergraduate Economics Students', Journal of Economic Education, 28, 350-368.

Ferber, M. (1995) 'The Study of Economics: A Feminist Critique', American Economic Review (papers and Proceedings), 85, 335-361.

Fitz-Gibbon, C.T. (1999) 'Long Term Consequences of Curriculum Choices with Particular Reference to Mathematics and Science', School Effectiveness and School Improvement, 10, 217-232.

Fitz-Gibbon, C.T. and Vincent, L. (1994) Candidates'Performance in Public Examination in Mathematics and Science, London, School Curriculum and Assessment Authority.

Gallagher, T., McEwan, A. and Knipe, D. (1997) 'Science Education Policy: A survey of the Participation of Sixth-Form Pupils in Science and other Subjects over a 10-year period, 1985-1995', Research Papers in Education, 12 (2), 121-142. 
Garratt, L. (1986) 'Gender Differences in Relation to Science Choice at A level', Educational Review, 38 (1), 67-77.

Garratt, L. (1985) 'Factors Affecting Subject Choice at A-level', Educational Studies, 11 (2), 127-132.

Greene B. (1997) `Verbal Abilities, Gender and the Introductory Economics Course: A New Look at Old Assumptions', Journal of Economic Education, 28 (Winter), 13-30.

Hansen, M. (1997) 'Social and Economic Inequality in the Educational Career: Do the Effects of Social Background Characteristics Decline', European Sociological Review, 13, 305-321.

Horvath, J., Beaudin, B. Q. and Wright, S. P. (1992) ‘Persisting in the Introductory Economics Course: An Exploration of Gender Differences', Journal of Economic Education, 23, 101-108.

Jensen, E. and Owen, L. (2000) 'Why Are Women Reluctant Economists? Evidence from Liberal Arts Colleges', American Economic Review Papers and Proceedings, 90, 466-470.

Jonsson, J. (1999) 'Explaining Sex Differences in Educational Choice: An Empirical Assessment of a Rational Choice Model', European Sociological Review, 15, 391-404.

McEwan, A., Curry, C. A. and Watson, J. (1986) 'Subject Preference at A level in Northern Ireland', European Journal of Science Education, 8(1), 39-49.

Reilly B. and Bachan, R. (2005) 'A Comparison of A-level Performance in Economics and Business Studies: How Much More Difficult is Economics?', Education Economics, 13 (1), 85-108.

Royal Society (2005) 'A-level science entries still a cause for concern', Press Release, www.royalsoc.ac.uk/news, accessed 18 August 2005.

Ryrie, A. C. (1981) 'Rules and Results: A Study of Later Years Schooling', SCRE Publication No. 75, Sevenoaks: Hodder and Stoughton.

Stables, A. and Stables, S. (1995) 'Gender Differences in Students Approaches to A-level Subjects: A Study of First-year A level Students in a Tertiary College', Educational Research, 37 (1), 39-51.

Stables, A. and Wikeley, F. (1997) 'Changes in Preference for and Perceptions of Relative Importance of Subjects During a Period of Educational Reform', Educational Studies, 23, 393-403.

Werfhorst, H., Sullivan, A. and Cheung, S. (2002) 'Social Class, Ability and Choice of Subjects in Secondary and Tertiary Education in Britain', Mimeo, Nuffield College Oxford. Available at http://www.nuff.ox.ac.uk/users/werfhorst/

Williams, M.L., Waldauer, C. and Duggal, V.G. (1992) 'Gender Differences in Economic Knowledge: An Extension of the Analysis', Journal of Economic Education, 23, 219-231.

\section{Notes}

1 All the awarding bodies in England introduced the new two-year A-level award in 2000. The AS award is aimed at broadening the candidate's range of studies (students in their first year of study are able to study, in most cases, up to five AS courses), postponing specialism until the second year of study. The AS accounts for $50 \%$ of the full A-level award and was first awarded in August 2001. Students are then able to choose which courses they intend to continue with after their first year of study (usually up to three) leading to the full A-level qualification in their second year of study. It should be noted that there are six grade classifications at A-levels: from a grade $A$ (highest pass grade) to a grade $E$ (lowest pass grade) and N/U (failure). 
2 New courses previously not available on the post-16 curriculum such as GNVQ Advanced Business (which may be viewed as a competing vocational optional subject), Theatre Studies, Media Studies, and Physical Education may appear more attractive to students in terms of their modes of assessment and their lesschallenging content. It is worth noting that the number of students sitting examinations in Communication Studies (which represents a group of subjects that were not established A-levels in the early 1990s) rose by $92 \%$ between 1992 and 2000 (DfEE).

3 The average GCSE score is calculated as the total GCSE points score achieved by a candidate divided by the number of GCSE subjects taken. The point scores are: $A^{*}=8$ points, $A=7, B=6, C=5, D=4, E=3, F=2, G=1$.

4 The following tariff was used: $A=10, B=8, C=6, D=4, E=2$ and $N / U=0$ (note that the current UCAS tariff, which is not used in this analysis, is: $A=120, B=100, C=80$, $\mathrm{D}=60, \mathrm{E}=40$ and $\mathrm{N} / \mathrm{U}=0$ ).

5 A likelihood ratio test was performed to test for any statistical justification for splitting the sample by gender. The Chi-squared statistic (46.72, with 34 degrees of freedom) proved only to be significant at $7 \%$, and the pooled model the more appropriate.

6 It should be stressed that the findings and conclusions relate to just one cohort drawn from 1998. It is conceded that a different picture may emerge in later years.

\section{Acknowledgments}

The authors would like to thank, Barry Reilly, Tom Bourner, Tim Fry, participants at the World Conference on Economic Education, held in Adelaide, July 13-16 2004 and two anonymous referees for constructive comments on earlier drafts of this paper.

\section{Contact details}

Ray Bachan

Brighton Business School

University of Brighton

Brighton BN2 4AT

UK

email:rb2@bton.ac.uk

Michael Barrow

Department of Economics

University of Sussex

Falmer

Brighton BN1 9QN

UK

email:m.m.barrow@sussex.ac.uk 